\title{
Health expectancy in New Zealand, 1981-1991: social variations and trends in a period of rapid social and economic change
}

\author{
Peter Davis, Patrick Graham, Neil Pearce
}

\begin{abstract}
Study objective-To assess social variations and trends in health expectancy over a period of rapid social and economic change.

Design-Cross sectional survey data on the association between social statusgender, socioeconomic class and ethnic group-and measures of health status at two points in time approximately a decade apart. The Sullivan method of calculating health expectancy was used.

Setting-The adult population of New Zealand in the periods $1980-81$ and 199293.

Participants-Representative samples of the adult civilian non-institutionalised population of $6891(1980-81)$ and 5873 (1992-93) respectively.

Main results-In comparison with life expectancy, adjusting for health status narrowed the gender gap but widened socioeconomic and ethnic differentials. These results were replicated for three measures-self reported health, mobility, and handicap-suggesting a robustness of outcome to specific indicators. Comparable data over the period of study were only available for the mobility measure. Increases in longevity appeared to be fully absorbed by minor disability. Ethnic and socioeconomic disadvantages remained static or widened for the 15-64 age group, suggesting a potential social polarisation in the disability transition.
\end{abstract}

Community Health, Faculty of Medicine and Health Science, University of Auckland P Davis

Department of Public Health and General Practice, Christchurch School of Medicine P Graham

Department of Medicine, Wellington

School of Medicine

$\mathrm{N}$ Pearce

Correspondence to: Professor P Davis,

Department of Public Health and General Practice,

Christchurch School of

Medicine, University of

Otago, PO Box 4345 ,

Christchurch, New Zealand.

Accepted for publication 3 March 1999
This disjunction is captured in the concept of health expectancy, a measure that broadens life expectancy beyond its sole reliance on mortality data to incorporate any defined state of health, both "positive" and "negative". ${ }^{3}$ The significance of such measures for policy purposes have been recognised, particularly in Europe,${ }^{4}$ and include the monitoring of health trends, issues of equity and resource allocation, service planning, and the assessment of health outcomes. $^{5}$

The use of health expectancy measures in research and policy analyses has shifted the terms of debate from simple mortality reduction to overall health improvement ${ }^{6}$ and encouraged the development of theories about long term changes in health status encompassing models of improvement ("compression of morbidity"), ${ }^{7}$ decline ("expansion of morbidity"), ${ }^{8}$ and maintenance of the status quo ("dynamic equilibrium"). ${ }^{9}$ It has also permitted a much more appropriate operationalisation of these theories with the deployment of the ratio of health expectancy to life expectancy. Hence for the three models outlined above we would expect, respectively, either an increase in the ratio, a decline, or a change conditional on severity. ${ }^{10}$

The application of the health expectancy concept to cross sectional data has also significantly illuminated debates about social variations in health. With this adjustment the gender differential in longevity is narrowedwith women living longer, but in extra years of minor disability ${ }^{11}$ - while socioeconomic and regional differences are increased. ${ }^{12}$ A similar pattern seems to hold for ethnic variations. ${ }^{13}$ These results have implications for decisions on resource allocation and health priorities. ${ }^{5}$

Despite its great potential, the impact of the health expectancy concept has been limited by a number of factors. Prominent among these has been a debate within the scientific community as to whether the use of cross sectional data is adequate to the task of tracking trends. ${ }^{14}$ The simulation study of Mathers and Robine has largely resolved this issue-in the affirmative, at least for those conditions in which trends in health status are evolving smoothly. ${ }^{15}$ A second issue concerns the potential for obtaining comparable estimates of health expectancy over both time and place-given the potential multiplicity of survey indicators. ${ }^{16}{ }^{17}$ This question remains in contention.

The focus of this paper is on the latter issue - the use of a range of indicators and their 
application to the analysis of social variations and trends in health expectancy in New Zealand over a period in which that country has undergone rapid social and economic change. ${ }^{18} 19$

\section{Methods}

DATA SOURCES

The Sullivan method of estimating health expectancy used in this paper combines information from standard population life tables with data on the prevalence of disability, handicap or other health problems. ${ }^{20}$ Life tables for the total male and female populations and gender specific tables for the Maori and non-Maori ethnic groups were obtained for the periods 1980-82 and 1990-92 from Statistics New Zealand, the country's central statistical agency. Prevalence data were also available from this source (see below).

As socioeconomic status (SES) specific life tables are not routinely calculated in New Zealand, we constructed our own tables using previously published SES specific mortality rates ${ }^{21}$ and standard life table methods. ${ }^{22}$ The published SES mortality rates were available for 10 year age groups from age 15 to 64 . Consequently our SES life tables were restricted to this age range and, for example, can only give the average number of years lived between ages 15 and 64 for a hypothetical cohort of men in a particular SES group. The amount by which the computed partial life expectancy between ages 15 and 64 falls short of its possible maximum of 50 years represents years of life lost because of premature mortality before age 65 (and is conceptually related to the notion of potential years of life lost). It should also be noted that, as the published SES mortality rates were for three year periods centred around 1976 and 1986, we extrapolated these rates to 1981 and 1991 respectively by applying the published rate ratios to the overall age specific mortality rates in those years.

Data on the prevalence of health problems and disabilities were drawn from two large surveys, the Social Indicators Survey (SIS) $(1980-81)^{23}$ and the Household Health Survey (HHS) (1992-3). ${ }^{24}$ These correspond closely to the period covered by the life tables. Both surveys were based on stratified multi-stage samples of the civilian population resident in private dwellings and therefore excluded the armed forces and people resident either in health care institutions or in prison. The sampling frame was also restricted to ages 15 and older in the SIS. Consequently the analyses reported here are restricted to ages 15 and older. The achieved samples size in the SIS was 6891, and the number aged greater than 15 years in the HHS was 5873.

From the HHS data we constructed three health problem indices. The first of these was a composite index based on two questions: the first, a screener, was a self report of any health problem or disability; the second, a follow up, reported the use of help with daily activities such as preparation of meals, shopping, housework and personal care because of the reported health problem. The screening question on health problems covered doctor or nurse identified long term problems (likely to last six months or more), hearing problems, sight problems, other physical problems, and psychiatric or psychological problems. The follow up question on use of help specified that the association was "because of this or any other long-term disability, illness or health problem".

The second health index was based on the concept of self assessed health. People were classified as being in good health if they assessed their overall health as "excellent" or "good" and not good if their assessment of their health was "not so good" or "poor."

The final measure of health status used was based on the ability to climb stairs. This specific functional item was selected because it was the only item directly comparable across the two survey years. People were classified as having "stair problems" if they responded "Yes but with difficulty" or "No, not at all" to the question "Can you walk up a flight of stairs without help from anyone else?" In 1981, the comparable question was "Can you walk up and down stairs?" Although the wording of the question was not identical across the two surveys we considered them sufficiently comparable for the purposes of the current analysis.

Following the provisional classification of health expectancy types drawn up by van de Water et $a l,{ }^{4}$ we will refer to these three measures as indicators of handicap free, healthy and disability free life expectancy respectively.

As already stated, these survey data omitted the adult non-civilian and institutional population of New Zealand. There is no nationally representative information on the prevalence of health problems among people resident in institutions or in the armed forces. For the purposes of our analysis, therefore, we made the assumption that age-gender specific problem prevalences among those in prison and in the armed forces do not differ markedly from the corresponding age-gender specific prevalences for the rest of the population. In any case these groups make up a small proportion of the population.

A greater analytical difficulty was presented by residents of health care institutions (hospitals and homes for the elderly) as these could be expected to have higher age specific health problem prevalences than the non-institutional population. We obtained census data on the age, gender and ethnic specific numbers resident in hospitals or homes for the elderly in 1981 and 1991. From these data we were able to compute the expectation of life resident in health care institutions and to adjust other health expectancy measures by this amount (see Computational issues below).

Numbers of residents in hospital or homes for the elderly were not available by SES. We therefore assumed that age specific prevalences of institutionalisation did not vary with SES. However, it should be noted that the prevalence of institutionalisation within the 15 to 64 age group was considerably less than one per cent and that for the male population the expectation of life in institutional care between 
Table 1 Health expectancy (HE) and life expectancy (LE), at ages 15 and 65 (1991). Years spent in different health states, and HE:LE ratio, by gender (approximate 95\% confidence intervals in parentheses)

\begin{tabular}{|c|c|c|c|c|c|}
\hline & \multicolumn{2}{|l|}{ Men } & \multicolumn{2}{|l|}{ Women } & \multirow[b]{2}{*}{$F-M^{*}$} \\
\hline & Years & $H E / L E$ & Years & $H E / L E$ & \\
\hline \multicolumn{6}{|l|}{ Age 15} \\
\hline self rated health OK & $51.3(50.3,52.3)$ & $87.2 \%(86.5,88.8)$ & $54.7(53.7,55.7)$ & $84.9 \%(83.3,86.4)$ & $3.4(2.0,4.8)$ \\
\hline able to climb stairs & $52.6(51.7,53.5)$ & $89.3 \%(87.9,90.8)$ & $54.5(53.5,55.5)$ & $84.6 \%(83.1,85.9)$ & $1.9(0.6,3.2)$ \\
\hline handicap free & $54.0(53.2,54.8)$ & $91.8 \%(90.5,93.0)$ & $56.4(55.6,57.2)$ & $87.6 \%(86.3,88.9)$ & $2.5(1.4,3.6)$ \\
\hline $\begin{array}{l}\text { life expectancy at } 15 \\
\text { Age } 65\end{array}$ & $58.8(58.6,59.0)$ & & $64.4(64.2,64.6)$ & & $5.6(5.5,5.7)$ \\
\hline self rated health OK & $10.1(9.3,10.9)$ & $68.2 \%(63.4,74.0)$ & $12.2(11.6,12.8)$ & $66.3 \%(62.7,70.2)$ & $1.1(0.1,2.1)$ \\
\hline able to climb stairs & $10.0(9.2,10.8)$ & $67.6 \%(62.5,73.1)$ & $10.2(9.5,10.9)$ & $55.4 \%(51.2,59.4)$ & $0.2(-0.9,1.3)$ \\
\hline handicap free & $10.9(10.2,11.6)$ & $73.6 \%(69.3,78.9)$ & $12.0(11.3,12.7)$ & $65.2 \%(61.6,69.1)$ & $1.1(0.1,2.1)$ \\
\hline life expectancy at 65 & $14.8(14.7,14.9)$ & & $18.4(18.3,18.5)$ & & $4.4(4.0,4.8)$ \\
\hline
\end{tabular}

^Difference: women-men (y).

ages 15 and 64 was only 0.2 years. Therefore the assumption of no SES variation in the prevalence of institutionalisation is likely to have a negligible effect either way on health expectancy estimates restricted to the 15 to 64 age group.

CLASSIFICATION OF SES

For our socioeconomic classification we used the Elley-Irving (E-I) SES scale, an occupational based classification commonly used in health and social research in New Zealand. ${ }^{25}$ The E-I system classifies people into one of six SES groups on the basis of respondent occupations coded according to the New Zealand standard classification of occupations (NZSCO).

Occupational coding in the SIS had been carried out at the two digit level of the NZSCO, while the SES mortality rates used in constructing life tables had been coded at the more detailed three digit level. From published census data for 1981 we were able to determine the distribution of people across the six E-I categories for each two digit occupational group. Using this information we developed a multiple imputation strategy after Rubin, ${ }^{26}$ which involved repeated stochastic allocation of E-I categories to the survey respondents on the basis of their two digit occupational code and the known distribution of E-I categories from the 1981 census for that code.

A multiple imputation procedure was also developed for the SES classification of survey respondents in the HHS. Although a three digit occupational code was available in the survey data set, this could not be directly translated into the E-I system because of changes in the NZSCO since the development of the E-I scale. However, we were able to access a double coded sample from the 1991 population census that contained both the old (1968) and new (1990) NZSCO codes for each person. ${ }^{27}$ From these data we were again able to develop a model for multiply imputing E-I categories using the recorded occupational code and the census information on the distribution of E-I categories for each occupational code.

COMPUTATIONAL ISSUES

We used the Sullivan method for computing health expectancy estimates. ${ }^{20}$ This approach incorporates health problem prevalences into standard population life tables, thereby parti- tioning life expectancy into the expectation of life with and without problems. Because data on the prevalence of health problems were available only for the population resident in private dwellings, we carried this procedure one step further by partitioning total remaining life expectancy into years spent in health care institutions, years spent outside institutions but with health problems, and years spent outside health care institutions and free of problems. The health expectancy estimates reported below correspond to the latter quantity.

Approximate $95 \%$ confidence intervals for health expectancy estimates were computed as the estimate plus or minus 1.96 standard errors, with standard errors computed using Mathers' method, ${ }^{28}$ which for ease of reference is outlined in the appendix. Standard error and confidence intervals for differences between groups and for differences over time were computed assuming statistical independence (of the group or time specific estimates). It should be noted that in the case of temporal comparisons this procedure provides confidence intervals that may be slightly conservative.$^{28}$ Confidence intervals for the ratio of health expectancy to total life expectancy were computed using an extension of Mathers' method. Details are given in the appendix.

\section{Results}

The presentation of results is in two sections. In the first part results are established for 1992-3 across all three measures of health expectancy for a standard set of social comparisonsnamely, gender, ethnic group, and SES. In the second section the analysis is extended to comparisons over time for all three sets of contrasts, using a single measure of health expectancy.

\section{SOCIAL COMPARISONS}

In table 1 data are presented for health expectancy estimates for the total male and female populations. Results-including gender differences-are outlined for the three measures of health expectancy at ages 15 and 65, together with the ratio of health expectancy to total life expectancy expressed as a percentage. As can readily be seen, the gender difference is smaller for all three health expectancy indices than it is for total life expectancy at both age levels, with the estimate based on the ability to climb stairs giving the smallest discrepancy. This is reflected in the health expectancy to life 
Table 2 Health expectancy (HE) and life expectancy (LE), at age 15 (1991). Years spent in different health states, and HE: LE ratio, by ethnicity and gender (approximate 95\% confidence intervals in parentheses)

\begin{tabular}{|c|c|c|c|c|c|}
\hline & \multicolumn{2}{|l|}{ Maori } & \multicolumn{2}{|l|}{ non-Maori } & \multirow[b]{2}{*}{$N M-M^{*}$} \\
\hline & Years & $H E / L E$ & Years & $H E / L E$ & \\
\hline \multicolumn{6}{|l|}{ Men } \\
\hline self rated health OK & $42.5(38.5,46.5)$ & $78.3 \%(71.4,86.0)$ & $51.8(50.8,52.8)$ & $87.5 \%(85.8,89.2)$ & $9.3(5.2,13.4)$ \\
\hline able to climb stairs & $42.4(39.0,45.8)$ & $78.1 \%(72.1,84.5)$ & $53.2(52.3,54.1)$ & $89.9 \%(88.4,91.3)$ & $10.8(7.3,14.3)$ \\
\hline handicap free & $45.9(43.0,48.8)$ & $84.5 \%(79.4,90.0)$ & $54.5(53.7,55.3)$ & $92.1 \%(90.8,93.4)$ & $8.6(5.6,11.6)$ \\
\hline $\begin{array}{l}\text { life expectancy at } 15 \\
\text { Women }\end{array}$ & $54.3(53.6,55.0)$ & & $59.2(59.0,59.4)$ & & $4.9(4.2,5.7)$ \\
\hline self rated health OK & $46.3(42.2,50.4)$ & $78.6 \%(72.0,85.7)$ & $55.3(54.3,56.3)$ & $85.3 \%(83.7,86.8)$ & $9.0(4.8,13.2)$ \\
\hline able to climb stairs & $45.1(41.6,48.6)$ & $76.6 \%(70.7,82.8)$ & $55.3(54.4,56.2)$ & $85.3 \%(84.0,86.8)$ & $10.2(6.5,13.9)$ \\
\hline handicap free & $48.1(44.7,51.5)$ & $81.7 \%(76.1,87.8)$ & $57.1(56.2,58.0)$ & $88.1 \%(86.8,89.4)$ & $9.0(5.4,6.7)$ \\
\hline life expectancy at 15 & $58.9(58.2,59.6)$ & & $64.8(64.6,65.0)$ & & $5.9(5.1,6.7)$ \\
\hline
\end{tabular}

^Difference: non-Maori-Maori (y).

expectancy ratio (HE/LE); in each case the percentage of life expectation spent in a condition of positive health is higher for men than it is for women. For example, at age 15 men can expect to live, on average, a further 58.8 years of which $87.2 \%$ will be self rated as being in "good health", in contrast with a figure of $84.9 \%$ for women.

Ethnic specific health expectancy estimates are reported separately for men and women in table 2. Only health expectancy at age 15 is reported because of the small number of older Maori in the 1992 HHS. While the ethnic group differences in total life expectancy at age 15 are substantial, the corresponding differences in health expectancy are consistently larger for all three measures. For men the difference in total life expectancy amounts to an advantage to non-Maori of 4.9 years, whereas the health expectancy differences are consistently about double that figure. The same holds for the female comparisons.

This relation reflects the fact that the prevalence of health problems and/or disabilities is much lower among non-Maori, a result that is captured in the ratio of health expectancy to total life expectancy; while this figureexpressed as a percentage - varies in the range $78 \%-85 \%$ for Maori, the comparable range for non-Maori is $85 \%-92 \%$. It should also be noted that the ethnic differential is similar for both men and women despite the latter's more favourable health profile. Note also that for each ethnic-group comparison the $95 \%$ confidence interval excludes zero. This indicates that although the confidence intervals for the non-Maori-Maori differences are wide, the observed ethnic group differences cannot be entirely accounted for by sampling variability.

In table 3 results are presented for SES differences. It should be noted that these data relate only to men in the age range $15-64$; it is in part because of this age ceiling that the variation between SES groups seems more subtle than the ethnic-group differences. Nevertheless, for all three measures the estimates for the combined classes 5 and 6 were markedly lower than the corresponding estimates for the combined classes 1 and 2. The advantage to classes 1 and 2 compared to classes 5 and 6 was similar for partial life expectancy (between ages 15 and 64) and for handicap free life expectancy, whereas the advantage to classes 1 and 2 was somewhat larger for the indicator of healthy life expectancy based on self reported health.

\section{COMPARISONS OVER TIME}

Analysis of change in health expectancy is restricted to the measure based on the ability to climb stairs, which, as discussed above, is the only comparable item in the SIS and HHS data sets. Consequently, in this section the term health expectancy will refer to the expectation of years in which stairs can be climbed without difficulty; also as discussed before, this can be taken as an indicator of disability free life expectancy.

Changes in both life and health expectancy at ages 15 and 65 for the total male and female populations are shown in the first two panels of table 4. While life expectancy increased by approximately two years at age 15 , and by 1.5 years at age 65, health expectancy remained essentially unchanged. This is reflected in the ratio of health expectancy to life expectancy; this declined for all comparisons over time in these two panels, particularly for those over the age of 65 . Gender differences in health expectancy at age 15 remained constant at about two years, and declined slightly from 0.6 to 0.2 years at age 65 .

In the third panel of the table data are presented on partial health and life expectancy

Table 3 Partial health expectancy (PHE) and partial life expectancy (PLE) between ages 15 and 64 (1991). Years spent in different health states and PHE:PLE ratio, by socioeconomic status:men only (approximate 95\% confidence intervals in parentheses)

\begin{tabular}{|c|c|c|c|c|c|}
\hline & SES $1 / 2$ & SES 3 & SES 4 & SES 5/6 & $1 / 2-5 / 6^{*}$ \\
\hline self rated health OK & $46.1(45.1,47.1)$ & $45.5(43.8,47.2)$ & $43.7(41.7,45.7)$ & $42.0(40.2,44.0)$ & $4.1(2.1,6.3)$ \\
\hline PHE/PLE (\%) & $97.0 \%(95.0,99.0)$ & $95.6 \%(92.1,99.3)$ & $93.7 \%(89.4,99.1)$ & $91.8 \%(87.7,96.1)$ & \\
\hline able to climb stairs & $46.4(45.3,47.5)$ & $45.4(43.2,47.6)$ & $45.1(43.5,47.3)$ & $43.5(41.9,45.1)$ & $2.9(1.0,4.9)$ \\
\hline PHE/PLE (\%) & $97.6 \%(95.2,1.0)$ & $95.5 \%(91.4,99.4)$ & $96.6 \%(93.4,1.0)$ & $95.2 \%(91.7,98.8)$ & \\
\hline handicap free & $46.6(45.9,47.3)$ & $46.8(46.2,47.5)$ & $44.9(43.7,46.1)$ & $44.5(43.6,45.4)$ & $2.1(0.9,3.3)$ \\
\hline PHE/PLE (\%) & $98.0 \%(96.5,99.5)$ & $98.2 \%(96.8,99.7)$ & $96.3 \%(93.7,98.9)$ & $97.4 \%(95.5,99.3)$ & \\
\hline partial life expectancy (15-64) & $47.6(47.4,47.8)$ & $47.6(47.4,47.8)$ & $46.7(46.5,46.9)$ & $45.7(45.5,45.9)$ & $1.9(1.6,2.2)$ \\
\hline
\end{tabular}

^Difference: SES 1/2-SES 5/6 (y). 
Table 4 Gender specific changes in health expectancy (HE), life expectancy, and HE:LE ratio between 1981 and 1992 at ages 15 and 65 and between ages 15 and 64 (approximate 95\% confidence intervals in parentheses)

\begin{tabular}{|c|c|c|c|c|c|c|}
\hline & \multicolumn{3}{|l|}{ Men } & \multicolumn{3}{|l|}{ Women } \\
\hline & 1981 & 1992 & $(1992-1981)^{*}$ & 1981 & 1992 & $(1992-1981)^{*}$ \\
\hline \multicolumn{7}{|l|}{ Age 15} \\
\hline able to climb stairs & 52.5 & 52.6 & $+0.1(-1.06,1.26)$ & 54.5 & 54.5 & $0.0(-1.30,3.01)$ \\
\hline life expectancy & 56.7 & 58.8 & $+2.1(1.83,2.37)$ & 62.5 & 64.4 & $+1.9(1.63,2.17)$ \\
\hline $\mathrm{HE} / \mathrm{LE}$ & $92.6 \%$ & $89.3 \%$ & $-3.3 \%(-5.38,-1.39)$ & $87.2 \%$ & $84.6 \%$ & $-2.6 \%(-4.60,0.71)$ \\
\hline \multicolumn{7}{|l|}{ Age 65} \\
\hline able to climb stairs & 9.9 & 10.0 & $+0.1(-0.96,1.16)$ & 10.5 & 10.2 & $-0.3(-1.38,0.78)$ \\
\hline life expectancy & 13.3 & 14.8 & $+1.5(1.30,1.70)$ & 17.1 & 18.4 & $+1.3(1.10,1.50)$ \\
\hline $\mathrm{HE} / \mathrm{LE}$ & $74.4 \%$ & $67.6 \%$ & $-6.8 \%(-14.89,0.11)$ & $61.4 \%$ & $55.4 \%$ & $-6.0 \%(-12.39,-0.09)$ \\
\hline \multicolumn{7}{|l|}{ Age $15-64$} \\
\hline able to climb stairs & 45.1 & 44.7 & $-0.4(-1.19,1.16)$ & 45.6 & 45.6 & $0.0(-0.83,0.83)$ \\
\hline partial life expectancy & 46.8 & 47.2 & $+0.4(0.25,0.55)$ & 48.1 & 48.4 & $+0.3(0.19,0.41)$ \\
\hline PHE/PLE & $96.4 \%$ & $94.7 \%$ & $-1.7 \%(-3.45,-0.01)$ & $94.8 \%$ & $94.2 \%$ & $-0.6(-2.30,1.02)$ \\
\hline
\end{tabular}

*Change over the period $1980-81$ to $1992-3$.

over the age range $15-64$. This is to provide comparability with the results presented in the remaining two tables for trends by ethnic group and by SES. The pattern of slightly improved life expectancy, but stationary or slightly declining health expectancy, were repeated here, albeit with more subtle changes. Overall, the gender differential remained static or declined.

As there were only two Maori respondents aged over 75 in the SIS, comparisons of ethnic specific changes over the study period were restricted to partial health expectancy between ages 15 and 64 . These estimates are shown in table 5. Although the ethnic group difference in partial life expectancy narrowed over the study period, the partial health expectancy differential remained approximately constant for men and widened for women. Non-Maori women were the only group to record an increase in partial health expectancy, and this gain was only 0.2 years. A modest increase in partial life expectancy was apparent in all groups, and consequently the partial health expectancy:life expectancy ratio declined for all groups.

In table 6 changes in partial health expectancy over the study period are outlined for four SES groupings. While a modest increase in life expectancy between ages 15 and 64 was recorded for all SES groups, only the combined groups 1 and 2 recorded an improvement in health expectancy. This resulted in a clearer SES gradient in health expectancy in 1992-3 than was apparent in 1981; it is evident that only for groups 1 and 2 did the ratio of partial health expectancy to partial life expectancy improve. However, the confidence intervals for the SES specific changes in health expectancy are wide and the data are consistent with a hypothesis of no change in health expectancy.

\section{Discussion}

The results reported in this study confirm other findings on social variation in health

Table 5 Changes in partial health expectancy (PHE), partial life expectancy (PLE), and PHE:PLE ratio between ages 15 and 64, over the period 1980-81 to 1992-3, by ethnicity and gender (approximate 95\% confidence intervals in parentheses)

\begin{tabular}{|c|c|c|c|c|c|c|}
\hline \multirow[b]{2}{*}{ Age 15-64 } & \multicolumn{3}{|l|}{$1980-81$} & \multicolumn{3}{|l|}{ 1992-3 } \\
\hline & non-Maori & Maori & $N M-M^{*}$ & non-Maori & Maori & $N M-M^{\star}$ \\
\hline \multicolumn{7}{|l|}{ Men } \\
\hline able to climb stairs & 45.3 & 40.6 & $4.7(1.95,7.46)$ & 44.9 & 40.1 & $4.8(2.02,7.57)$ \\
\hline partial life expectancy & 47.0 & 45.1 & $1.9(1.43,2.37)$ & 47.3 & 45.8 & $1.5(1.15,1.85)$ \\
\hline PHE/PLE $(\%)$ & 96.4 & 90.0 & $6.4(0.48,12.63)$ & 94.9 & 87.5 & $7.4(0.92,13.38)$ \\
\hline \multicolumn{7}{|l|}{ Women } \\
\hline able to climb stairs & 45.8 & 42.6 & $3.2(0.74,5.66)$ & 46.0 & 41.0 & $5.0(2.30,7.70)$ \\
\hline partial life expectancy & 48.2 & 46.5 & $1.7(1.30,2.10)$ & 48.5 & 47.3 & $1.2(0.91,1.49)$ \\
\hline PHE/PLE (\%) & 94.7 & 91.6 & $3.1(-2.01,8.28)$ & 94.8 & 86.7 & $8.1(2.27,13.45)$ \\
\hline
\end{tabular}

^Difference: non-Maori-Maori.

Table 6 Changes in partial health expectancy (PHE), partial life expectancy (PLE) and PHE:PLE ratio for ages 15 to 64, over the period 1980-81 to 1992-3 by socioeconomic status:men only (approximate 95\% confidence intervals in parentheses)

\begin{tabular}{llllll}
\hline & SES 1 and 2 & SES 3 & SES 4 & SES 5 and 6 & SES 1/2-SES 5/6* \\
\hline 1980-81 & & & & & \\
able to climb stairs (PHE) & $45.1(43.4,46.8)$ & $45.5(44.5,46.6)$ & $45.5(44.7,46.3)$ & $44.1(43.2,47.0)$ & $1.0(-0.9,2.9)$ \\
partial life expectancy & $47.2(47.0,47.4)$ & $47.0(46.8,47.2)$ & $46.6(46.4,46.8)$ & $45.2(45.0,45.4)$ & $2.0(1.7,2.3)$ \\
PHE/PLE (\%) & $95.6(92.0,99.2)$ & $96.8(94.7,99.0)$ & $97.5(95.8,99.3)$ & $97.6(95.6,99.4)$ & $-2.0(-6.0,2.4)$ \\
1992-3 & & & & \\
able to climb stairs (PHE) & $46.4(45.3,47.5)$ & $45.4(43.2,47.6)$ & $45.1(43.5,47.3)$ & $43.5(41.9,45.1)$ & $2.9(1.0,4.9)$ \\
partial life expectancy & $47.6(47.4,47.8)$ & $47.6(47.4,47.8)$ & $46.7(46.5,46.9)$ & $45.7(45.5,45.9)$ & $1.9(1.6,2.2)$ \\
PHE/PLE (\%) & $97.6(95.2,1.0)$ & $95.4(91.4,99.4)$ & $96.6(93.4,1.0)$ & $95.2(91.7,98.8)$ & $2.4(-1.9,6.6)$ \\
1980-81 to 1992-3† & & & & \\
able to climb stairs (PHE) & $+1.3(-0.8,3.5)$ & $-0.1(-2.3,2.1)$ & $-0.4(-2.2,1.5)$ & $-0.6(-2.5,1.2)$ & \\
partial life expectancy & $+0.4(0.1,0.7)$ & $+0.6(0.3,0.9)$ & $+0.1(-0.2,0.4)$ & $+0.5(0.2,0.8)$ & \\
PHE/PLE (\%) & $+2.0(-2.6,6.1)$ & $-1.4(-6.0,3.0)$ & $-0.9(-4.6,2.81)$ & $-2.3(-6.2,1.8)$ & \\
\hline
\end{tabular}

*Difference: (SES 1 and 2)-(SES 5 and 6). †Change over the period 1980-81 to 1992-3. 
expectancy ${ }^{11}$ and extend them to the case of ethnicity. The paper presents both the absolute level of health expectancy and the ratio of health expectancy to life expectancy, and this allows us to take into account the quality as well as the longevity of life. This adjustment serves to narrow the gender gap - to vanishing point for the over 65 age group-but widens ethnic and SES differentials in health status, results that are consistent with previous research for New Zealand. ${ }^{29}$

This finding holds for all three measures of health expectancy, with the exception of SES differences in handicap free life expectancy (which are similar to those for partial life expectancy). This latter result may simply reflect the uniformly low prevalence of serious health problems and disability in younger age groups with the restriction of our SES analyses to ages 15 to 64 . Overall, however, our results indicate that social variation in health expectancy appears reasonably robust to the choice of health status measure. This outcome is consistent with a literature that suggests that, while apparently innocuous changes in the wording of questionnaires can lead to major differences for specific estimates of disability, ${ }^{17}$ the general thrust of results from applying different methods is to sustain what are essentially similar overall conclusions. ${ }^{16}$ Despite concerns about the possible masking effect of social variations in self reported health, ${ }^{30}$ there are also encouraging signs that variations in the models of health used by different population groups may not be as great as had previously been suggested. ${ }^{31}$ There is also growing evidence that self reports are highly predictive of health status. $^{32} 33$

Apart from extending the analysis of social variations in health expectancy to ethnicity and demonstrating the consistency of such results over a range of indicators, this paper has also attempted to extend the analysis of such variations over time and assess the fit of different models of the disability transition. However, while the cross sectional analysis had available to it indicators approximately equivalent to three types of health expectancy-handicap free, disability free and healthy life expectancy - only one of these-disability free as assessed by stair climbing-was available in a comparable form over the two surveys spanning the period 1980-81 to 1992-3. Nevertheless, our confidence in the robustness of this single measure may be strengthened by the consistency of the cross sectional analyses carried out for all three measures deployed from the 1992-3 HHS. The effects of the slight changes in wording of the available measure over the two surveys probably balance out. While it might be expected that it would be easier just to climb up stairs (the second survey) rather than up and down (the first survey) - thus possibly reducing the reported problem prevalence-the fact that the second time the question explicitly also stated "without help from anyone else" could have contributed to a slight increase in reported problem prevalence. On balance these effects may just cancel out.
KEY POINTS

- The assessment of health expectancy seems to be reasonably robust to the choice of specific indicator.

- Ethnic health differences are more marked when assessed by health expectancy rather than longevity of life.

- Health expectancy can provide a sensitive indicator of the impact of rapid social and economic change on the health of subpopulations.

- Health improvement strategies must be developed that counter the potential for social polarisation in the disability transition.

While the study has extended the analysis of social variations to the case of ethnicity for both cross sectional and time series data, a question arises about the inter-relation between ethnic affiliation and SES and the extent to which results for these two dimensions are confounded. For example, while approximately half of all Maori men in both surveys were classified in SES groups 5 and 6, this was only true of a quarter of non-Maori. Because of the small numbers involved it was not possible to make SES-ethnic group specific estimates. However, previous research in New Zealand suggests that only about $20 \%$ of Maori-nonMaori differences in overall mortality was attributable to differences in SES. ${ }^{34}{ }^{35}$

Further confirmation of the possible independence of SES and ethnicity is research suggesting that despite evidence that health models may not be all that different for most population groups ${ }^{31}$ this might not be true for ethnic groups. Thus indigenous Australian people report similar or better health than other Australians despite having much worse objective health statistics (C Mathers, Ninth Meeting of the Network on Health Expectancy (REVES), Rome, 1996). If Maori were to follow this pattern, the health expectancy differences reported here between indigenous and other New Zealanders would be conservative.

Taking the health expectancy:life expectancy ratio as our statistical criterion after Robine, ${ }^{10}$ results from this study are clearly not consistent with any simple "compression of morbidity" (or health improvement) model of the disability transition because, while life expectancy has increased over the period of study, health expectancy has remained static and even declined slightly for some groups. In this respect, the results are similar to those described for Australia over almost exactly the same period by Mathers, ${ }^{36}$ although in the absence of data on more severe categories of disability it is not possible to say whether these findings sustain an "expansion of morbidity" or a "dynamic equilibrium" model.

A unique aspect of this study, however, is the potential it provides for tracking not just overall levels in health expectancy but also social variation. This is particularly pertinent given the rapidity of social and economic change 
experienced by New Zealand over the decade from the mid-1980s. Taking partial life expectancy over the age range 15-64 as our measure, overall levels seem to have improved over the period of study for all social comparison groups - with gender, ethnic and SES differences remaining largely unchanged. However, when we take the ratio of partial health expectancy to partial life expectancy as our indicator, we see that health status has declined or remained static for all comparison groupswith the exception of the more advantaged groups of non-Maori women and higher SES men. This highlights the potential importance of the choice of population health status indicator when exploring the impact of social and economic policy changes on social variation in health status.

One caveat on our results concerns the problems with occupational classification noted above; the SES comparisons reported here should be interpreted cautiously, therefore. The multiple imputation approach adopted to stochastically allocate SES codes on the basis of partial occupational information, accurately reflects the additional uncertainty attributable to the missing occupational information and provides, as a by product, an estimate of the inflation in variance due to missing information. ${ }^{26}$ Thus, for the $1980-81$ data, estimates of this excess variance ranged from $1 \%$ to $7 \%$, whereas for the $1992-3$ data estimates ranged from $8 \%$ to $36 \%$, indicating that the amount of missing occupational information was greater for this second data set.

Yet, despite this finding the SES gradient in health expectancy was clearer for this data set than for the 1980-81 data (a result that seems unlikely to be explained by misclassification effects as any such effects are likely to have been greater for the 1992-3 data). However, as with all epidemiological analyses, the confidence intervals reported here should probably be interpreted as providing a lower bound on total uncertainty. It should also be noted that there was no significant shift in SES distribution over the period of the study, and hence issues of potential selection bias do not arise. Thus, while $29 \%$ of male respondents in the first survey were classified in SES groups 5 and 6 , this was still true of $26 \%$ in the second survey.

The empirical results from this study hint at a potential socially differentiated version of existing theories of the disability transition. ${ }^{2}$ Under this amended model social groups with an initial health expectancy profile that is relatively advantaged conform to a model of "compressed morbidity", while those who start from a relatively disadvantaged position follow either an "expansion of morbidity" or a "dynamic equilibrium" model.

Thus, for the 15-64 age range that provides the core analysis in this paper, women in general, non-Maori women in particular, and also higher SES men, all reported superior (partial) health expectancy at the beginning of the period of study - both in absolute terms and as a percentage of partial life expectancyand then proceeded to record either a stable or slightly improved health expectancy profile a decade later. The converse held for the other groups; health expectancy was relatively disadvantaged at the beginning of the period and then failed to improve and even declined slightly.

The concept of health expectancy has been put to the service of a number of practical and analytical purposes. For some it is seen as the outcome criterion by which health care organisations should be judged in a competitive market ${ }^{6}$; for others it provides a key policy tool in managed systems. ${ }^{5}$ Analytically, this approach has been fruitful in the development of theories about the disability transition. ${ }^{79}$ While international comparisons over time seem to support the model of dynamic equilibrium (the spread of light or moderate but not severe levels of disability or handicap), ${ }^{3}$ such analyses have failed to heed the relevance of wider equity issues and take full account of the impact of social variation. ${ }^{37}$ The empirical results from this study suggest that - at least for disability free life expectancy over the 15-64 age range - a more socially differentiated theory is needed, one that recognises the potentially polarising impact of existing social structures on the shape of the disability transition and the distribution of its benefits.

We are grateful to Colin Mathers for his advice and encouragement and to Johan Mackenbach for comments on an earlier draft of this paper.

Funding: The Health Research Council of New Zealand is responsible for funding this research (under a limited budget respons and providing this rearch (under a linited budget grant) and providing salary support for both Patrick Graham (as a biostatistical consultant) and Neil Pearce (under a programm
grant with the Wellington Asthma Research). grant with the Wellington Ast

\section{Appendix}

STANDARD ERRORS AND CONFIDENCE INTERVALS FOR HEALTH EXPECTANCY INDICES

Mathers ${ }^{28}$ derived the following expression for the variance of the estimated health expectancy at age a:

$V\left(H L E_{a}\right)=\frac{1}{l_{a}^{2}}\left\{\sum_{i=a}^{i=w-1} l_{i}^{2}\left[\left(1-f_{i}\right) x_{i}\left(1-d_{i}\right)+H L E_{i+1}\right]^{2} V\left(p_{i}\right)+\sum_{i=a}^{i=w} L_{i}^{2} V\left(d_{i}\right)\right\}$

where

$\mathrm{HLE}_{\mathrm{i}}$ is the health expectancy for a person entering the ith age interval;

$1_{i}$ denotes the number of people in the hypothetical life table cohort surviving to the start of the ith age interval;

$\mathrm{w}$ is the final age interval;

$f_{i}$ is the fraction of the ith age interval lived by those dying in that interval, $\mathrm{f}$ usually being set at about 0.5 unless there is empirical evidence available suggesting some other value;

$\mathrm{x}_{\mathrm{i}}$ is the length of the ith age interval;

$\mathrm{p}_{\mathrm{i}}$ is the estimated conditional probability of surviving to the start of the $(i+1)$ th age interval, given survival to the start of the ith interval;

$\mathrm{L}_{\mathrm{i}}$ denotes the person years accumulated by the hypothetical life table cohort as they move through the ith age interval;

$\mathrm{d}_{\mathrm{i}}$ is the estimated disability or health problem prevalence for the ith age group;

and $\mathrm{V}(\mathrm{)}$ denotes the variance of the statistic in parentheses.

If, in the above expression, the disability prevalences, $\mathrm{d}_{\mathrm{i}}$, are set to zero, and health expectancy is replaced by total life expectancy, $\left(\mathrm{LE}_{\mathrm{i}}\right)$ - the first component of the expression for $\mathrm{V}\left(\mathrm{HLE}_{\mathrm{a}}\right)$-is just the variance of the total life expectancy; that is: 
$\mathrm{V}\left(L E_{a}\right)=\frac{1}{l_{a}^{2}} \sum_{i=a}^{i=w-1} l_{i}^{2}\left[\left(1-f_{i}\right) x_{i}+L E_{i+1}\right]^{2} V\left(p_{i}\right)$

This is the expression derived by Chiang. ${ }^{22}$

The above formulas follow from applying the delta variance approximation method ${ }^{38}$ to the total life expectancy and health expectancy estimates, written in terms of the conditional survival probabilities. ${ }^{22}{ }^{28}$ The derivations of these formulas assume that the age specific survival probabilities and age specific health problem prevalences are mutually independent. Consequently, the variance formulas given above are not appropriate for health expectancy estimates constructed from smoothed age specific estimates, although they can be extended to deal with this situation via the multivariate delta method. ${ }^{38}$ Age specific survival probabilities and health problem prevalences will usually be approximately independent because the prevalence estimates are typically based on a survey sample constituting only a small fraction of the population for which mortality statistics are available.

A minor extension of Mathers' method, involving application of the multivariate delta method, ${ }^{38}$ yields the following expression for the covariance of life expectancy and health expectancy indicators:

$\operatorname{Cov}\left(L E_{a}, H L E_{a}\right)=$

$\frac{1}{l_{a}^{2}}\left\{\sum_{i=a}^{i=w-1} l_{i}^{2}\left[\left(1-f_{i}\right) x_{i}+L E_{i+1}\right]\left[\left(1-f_{i}\right) x_{i}\left(1-d_{i}\right)+H L E_{i+1}\right] V\left(p_{i}\right)\right\}$

Assuming that the natural logarithm of the health expectancy to total life expectancy ratio, $\mathrm{R}_{\mathrm{a}}=\mathrm{HE}_{\mathrm{a}} / \mathrm{LE}_{\mathrm{a}}$, is normally distributed, a further application of the delta method yields the following expression for the variance of $\ln \left(R_{a}\right)$ :

$$
\begin{aligned}
& \mathrm{V}\left(\operatorname{in}\left(R_{a}\right)\right)=V\left(\operatorname{in}\left(H E_{a}\right)-\operatorname{in}\left(L E_{a}\right)\right)= \\
& \frac{1}{H E_{a}^{2}} V\left(H E_{a}\right)-\frac{2 \operatorname{Cov}\left(H E_{a}, L E_{a}\right)}{\left(H E_{a}\right)\left(L E_{a}\right)}+\frac{1}{L E_{a}^{2}} V\left(L E_{a}\right)
\end{aligned}
$$

Approximate $95 \%$ confidence intervals for $\mathrm{R}_{\mathrm{a}}$ can be obtained as

$\exp \left(\ln \left(R_{a}\right) \pm 1.96\left(V\left(\ln \left(R_{a}\right)\right)^{1 / 2}\right)\right.$.

As the health expectancy to total life expectancy ratio must lie between zero and one, the logit transform, log$\mathrm{it}(\mathrm{R})=\ln (\mathrm{R} /(1-\mathrm{R}))$, is another candidate transformation to achieve approximate normality. The delta method variance approximation for the logit transformed health expectancy to life expectancy ratio is given by:

$$
\begin{aligned}
& \left(\operatorname{logit}\left(R_{a}\right)\right)=\frac{1}{H E_{a}^{2}} V\left(H E_{a}\right)- \\
& \frac{2\left[\operatorname{Cov}\left(H E_{a}, L E_{a}\right)-V\left(H E_{a}\right)\right]}{\left(H E_{a}\right)\left(L E_{a}-H E_{a}\right)}+\frac{V\left(H E_{a}\right)-2 \operatorname{Cov}\left(H E_{a}, L E_{a}\right)+V\left(L E_{a}\right)}{}
\end{aligned}
$$

Approximate confidence intervals for $R_{a}$ can be obtained by back transforming the end points of confidence intervals for $\operatorname{logit}\left(\mathrm{R}_{\mathrm{a}}\right)$ using the inverse logit transformation $\operatorname{logit}^{-1}(\mathrm{Y})=\exp (\mathrm{Y}) /(1+\exp (\mathrm{Y}))$. This approach was not explored in the current paper; however some preliminary investigation suggested that, for the current analysis, intervals for the health expectancy to life expectancy ratio based on the logarithmic approximation agree closely with Monte-Carlo intervals obtained by simulating from a bivariate normal distribution with mean $\left(\mathrm{HE}_{\mathrm{a}}, \mathrm{LE}_{\mathrm{a}}\right)^{\mathrm{T}}$, where the superscript $\mathrm{T}$ denotes matrix transpose, and the variances and covariance for health and total life expectancy defined above.

Confidence intervals for temporal or between group differences in health expectancy to life expectancy ratios were obtained by Monte-Carlo methods, simulating from the appropriate independent bivariate normal distributions. For analyses involving multiply imputed estimates, estimated variances contain a between imputation component, reflecting the additional uncertainty attributable to missing information. Moreover confidence intervals are based on t-distributions rather than normal distributions. ${ }^{26}$

1 Crimmins EM. Mixed trends in population health among

2 Myers GC, Lamb VL. Theoretical perspectives on healthy Myers GC, Lamb VL. Theoretical perspectives on healthy
life expectancy. In: Robine JM, Mathers CD, Bone MR, et life expectancy. In: Robine JM, Mathers CD, Bone MR, et
al, eds. Calculation of health expectancies, harmonization, consensus achieved and future perspectives. Colloques INSERM Vol. 226. Paris: John Libbey Eurotext and Les Editions INSERM, 1993:109-19.

3 Robine JM, Romieu I, Cambois E. Health expectancies and current research. Reviews in Clinical Gerontology 1997;7:7381

4 van de Water HPA, Perenboom RJM, Boshuizen HC. Policy relevance of the health expectancy indicator; an inventory in European Union countries. Health Policy 1996;36:11729.

5 Bone MR, Bebbington AC, Jagger C, et al. Health expectancy and its uses. London: HMSO, 1995.

6 Kindig DA. Purchasing population health: aligning financial incentives to improve health outcomes. Health Serv Res 1998;33:223-42.

7 Fries JF. Aging, natural death, and the compression of morbidity. N Engl f Med 1980;303:130-5.

8 Olshansky SJ, Rudberg MA, Carnes BA, et al. Trading off longer life for worsening health: the expansion of morbidity hypothesis. F Aging Health 1991;3:194-216.

9 Manton KG. Changing concepts of morbidity and mortality in the elderly population. Milbank Q/Health Soc 1982;60: $183-244$.

10 Robine JM. Disability-free life expectancy trends in France: 1981-1991, international comparisons. In: Mathers C, McCallum J, Robine JM, eds. Advances in health expectancies: Proceedings of the 7 th Meeting of the International February 1994. Canberra: Australian Institute of Health and Welfare, 1994:43-51.

11 Robine JM, Mathers C, Brouard N. Trends and differentials in disability-free life expectancy: concepts, methods, and findings. In: Carelli G, Lopez A, eds. Health and mortality among elderly populations. Oxford: Clarendon Press, 1996: 182-201.

12 Bebbington AC. Regional and social variations in disability-free life expectancy in Great Britain. In: Robine M, Mathers CD, Bone MR, et al, eds. Calculation of health expectancies, harmonization, consensus achieved and future perspectives. Colloques INSERM Vol. 226. Paris: John Libbey Eurotext and Les Editions INSERM, 1993: 175-91.

13 Guralnik JM, Land KC, Blazer D, et al. Educational status and active life expectancy among older blacks and whites. $N$ Engl f Med 1993;329:110-16.

14 Barendregt JJ, Bonneux L, Van der Maas PJ. Health expectancy: an indicator for change? $\mathcal{f}$ Epidemiol Community Health 1994;48:482-7.

15 Mathers CD, Robine JM. How good is Sullivan's method for monitoring changes in population health expectancies. f Epidemiol Community Health 1997;51:80-6.

16 van Ginneken JKS, Dissevelt AG, van de Water HPA, et al. Results of two methods to determine health expectancy in Results of two methods to determine health expectancy in
the Netherlands in 1981-1985. Soc Sci Med 1991;32:1129the Net

17 Picavet HSJ, van den Bos GAM. Comparing survey data on functional disability: the impact of some methodological differences. F Epidemiol Community Health 1996;50:8693

18 Kelsey J. The New Zealand experiment: $A$ world model for structural adjustment? Auckland: Auckland University Press/ Bridget Williams Books, 1995.

19 Castles F, Gerritsen R, Vowles J, eds. The great experiment. Labour parties and public policy transformation in Australia 1996.

20 Sullivan D. A single index of mortality and morbidity. Health Services and Mental Health Administration (HSMHA) Health Reports 1971;86:347-54.

21 Pearce N, Marshall S, Borman B. Undiminished social class mortality differences in New Zealand men. $N Z$ Med $\mathcal{f}$ 1991;104:153-6.

22 Chiang CL, Introduction to stochastic processes in biostatistics. New York: John Wiley, 1968:202-39.

23 Department of Statistics. Report on the Social Indicators Survey. Wellington, New Zealand: Department of Statistics, Depart
vey. W
1984.
Statistics

24 Statistics New Zealand, Ministry of Health. A picture of health. Wellington, New Zealand: Statistics New Zealand and Ministry of Health, 1993.

25 Elley W, Irving J. Revised socioeconomic index for New Zealand. NZ $\mathcal{F}$ Educational Studies 1976;11:25-36.

26 Rubin DB. Multiple imputation for non response in surveys. New York: John Wiley, 1987.

27 Davis P, McLeod K, Ransom M, et al. The New Zealand Socioeconomic Index of Occupational Status (NZSEI). Research Report \#2, Technical Report Series. Wellington: Statistics New Zealand, 1997.

28 Mathers CD. Heath expectancies in Australia, 1981 and 1988. Canberra ACT: Australian Institute of Health Publications, 1991 .

29 Graham P, Davis P. Life expectancy free of disability: a composite measure of population health status. Community Health Studies 1990;XIV:138-45. 
30 Elstad JI. How large are the differences - really? Selfreported long-standing illness among working class and middle class men. Sociology of Health and Illness 1996;18

31 van Dalen H, Williams A, Gudex C. Lay people's evaluations of health: are there variations between different subgroups? f Epidemiol Community Health 1994;48:24853.

32 Blank N, Diderichsen F. The prediction of different experiences of long-term illness: a longitudinal approach in Sweden. F Epidemiol Community Health 1996;50: 156-61.

33 Moller L, Kristensen TS, Hollnagel H. Self rated health as a predictor of coronary heart disease in Copenhagen,
34 Pearce NE, Davis PB, Smith AH, et al. Mortality and social class in New Zealand. III: Male mortality by ethnic group.

35 Pearce NE, Pomare E, Marshall, et al. Mortality and social class in Maori and nonMaori New Zealand men: changes between 1975-1977 and 1985-87. NZ Med F 1993;106: 193-6.

36 Mathers C. Trends in health expectancies in Australia 1981-1993. Fournal of the Australian Population Association 1996;13:1-15

37 Whitehead $M$. The concepts and principles of equity and health. Int 7 Health Serv 1992;22:429-45.

38 Agresti A. Categorical data analysis. New York: John Wiley, 1990:422-5. 